Editorial Manager(tm) for Advances in Applied Ceramics: Structural, Functional and

Bioceramics

Manuscript Draft

Manuscript Number: AAC200R2

Title: Low cost ceramic moulding composites: - Materials and manufacturing technology

Article Type: Original Research Paper

Keywords: Metal silicates; moulding composites; compounding; processing; glass fibre; fillers; viscosity

Corresponding Author: Dr Guogang Ren, PhD

Corresponding Author's Institution: Queen Mary, University of London

First Author: Guogang Ren, PhD

Order of Authors: Guogang Ren, PhD; Guogang Ren, PhD; Paul J Hogg, PhD

Abstract: Low cost ceramic moulding compound/composites are composed of inorganic metal silicates, fillers and different types of chopped fibre reinforcements, such as glass fibres. This research investigated manufacturing process of a series of ceramic moulding compounds that could be moulded at modest temperature $\left(\sim 150^{\circ} \mathrm{C}\right)$ and pressure. The process replicates the polymer dough moulding compounds as fibre reinforced polymeric moulding composites(FRP). The conventional polymeric matrix of the DMC has been replaced by a soluble metal silicates based on an inorganic system which can be compounded with fibres, minerals or synthetic fillers and hardening additives to produce a thick paste or a doughy substance(ceramic DMC/CDMC). The CDMC compounds demonstrated a good handle-ability and can be adjusted by the viscosity of the matrix through the use of amount of fillers and additives. The mechanical properties of the compounds have been tested and additional formulation changes have been introduced to maintain desirable processing characteristics...

Suggested Reviewers: 


\title{
Low cost ceramic moulding composites: - Materials and manufacturing technology
}

G Ren*, P J Hogg* and D H Woolstencroft**

\begin{abstract}
Low cost ceramic moulding compounds/composites (CMC) are composed of inorganic metal silicates, fillers and different types of chopped fibre reinforcements, such as glass fibres. This research investigated manufacturing process of a series of ceramic moulding compounds that could be moulded at modest temperature $\left(\sim 150^{\circ} \mathrm{C}\right)$ and pressure $(0 \sim 8 \mathrm{MPa})$. This manufacturing process replicated the polymer dough moulding compounds as fibre reinforced polymeric moulding composites or Dough Moulding Compounds (DMC). The conventional polymeric matrix of DMC has been replaced by a soluble metal silicates based on an inorganic system which can be compounded with fibres, minerals or synthetic fillers and hardening additives, to produce a thick paste or a doughy substance -so called Ceramic Dough Moulding Compounds (CDMC). The CDMC demonstrated a good handle-ability and can be adjusted by the viscosity of the matrix through the use of various amounts of fillers and additives. The mechanical properties of the compounds have been tested and additional formulation changes have been introduced to maintain desirable processing characteristics.
\end{abstract}

Dr Ren (g.ren@qmul.ac.uk) was in the Department of Materials, Queen Mary, University of London. He is now in the University of Hertfordshire, Hatfield AL10 9AB, UK. Professor P J Hogg is now in the University of Manchester, Manchester M60 1QD. Dr Woolstencroft is with Matrice Technology, Poulton, Lancs. FY6 8GD, UK.

Keywords: ceramic silicates, moulding, composites, compounding, processing, glass fibre, fillers, viscosity.

\section{Introduction}

It is well known that ceramic materials can provide good fire resistance and thermal stability at elevated temperature. However, due to their nature of the bonding within the composition and molecular structures, they are very brittle and considered as unreliable or inappropriate in many engineering applications ${ }^{1,2,3}$. Although advanced ceramic composites overcome these problems by greatly improving the material's toughness, the high cost of raw materials and complexity in processing are still the obstacles to their widespread applications ${ }^{4}$. The main purposes of this research paper is to investigate the processability and selection of raw materials for developing a ceramic silicates -based, fibre-reinforced, fire-resistant composite system using low-cost metal silicates as a bonding matrix. This matrix was incorporated with some low cost minerals, synthetic materials, and reinforcing fibres through an existing mature process to form the CDMC very similarly a ceramic sheet moulding compounds (CSMC). This composite material would be adapted and replicated using the traditional DMC/SMC manufacturing processes which were long being used for fibre reinforced polymer moulding composites. The intention of this paper was to approve the tailored process to fit into the same production cycle as polymer matrix DMC.

Ceramic materials have considerable attraction for use in applications where the service temperature is high and fire performance and non-combustibility are important. Unfortunately most monolithic ceramic materials are extremely brittle which limits their use for structural applications. Incorporation of fibres into a low cost ceramic matrix provides a mechanism for improving toughness by crack stopping and stress shielding, particularly if the interface is relatively weak ${ }^{5}$. While this has been not significant relative to monolithic ceramics, the toughness of such materials has never approached those of polymer-based composites ${ }^{6}$. With a brittle matrix, the mechanical properties are highly affected by the fibre types and fibre/matrix interfacial properties ${ }^{2,3}$, which are a reflection of the formulation, moulding conditions and post curing, etc. The properties of the composite system were found depending on a number of materials and processing variables ${ }^{3,7}$.

Some other matrix systems could be found in applications when specific properties are required from the composite that cannot be provided by a polymeric system. Metallic and ceramic composites are expensive with the additional cost partly due to the raw materials involved (especially if very high temperature fibre reinforcement is required) and the processing routes required. For these reasons, metallic and ceramic matrix composites such as CDMC were designed to provide high performance to justify the costs.

Fibre reinforced composite materials for industrial applications have traditionally been based on organic polymeric matrices. Low pressure processing of liquid thermosetting resins reinforced with fibres ranging in cost and performance from carbon to glass has enabled a very diverse range of materials to find applications in industrial sectors, including aerospace, automotive, marine, chemical plants and building constructions. These materials are frequently cost effective relative to competitive engineering materials such as aluminium and steel particularly when a complete lifecycle analysis is undertaken that includes designing, tooling, manufacturing installation, maintenance, and repairing costs ${ }^{8}$.

A ceramic polymer based Dough Moulding Compound process is developed to provide simple, low cost, fast production routes that give flexibility in design and low cost for tooling. Therefore, the aim of this research was to develop a new type of ceramic matrix composites that combine toughness, strength, and the process-ability to provide a cost effective structural and a fire resistant material. This paper is one of a series which report on the 
manufacturing of the composites where all other constituents and the process cycles are kept constant. The emphasis of the paper will be on the influence of the matrix system, viscosity development and filler content, etc. and basic comparison mechanical properties. Specific details of the matrix system are not provided due to commercial confidentiality. Last paper published in this topic was in impact properties of the materials in the Journal of British Ceramic Transactions 8.

\section{Experimental design of materials, compounding, and moulding}

Ceramic resin system - liquid, solid silicates and hardeners

The silicates are available commercially with a variety of different water to solid silicate ratios. A list of solutions and powders of metal silicates supplied by a manufacturer, Crosfield in Kent, England is given in Table 1 and Table 2. In order to achieve the minimum water content in the final product, solution 079 and powder P60 were selected as a base liquid and solid form of silicates for the compounding. P60 (Crystal M) is with the water content $20 \%$ and is the power type of Solution 079 with the same $\mathrm{SiO} 2: \mathrm{Na} 2 \mathrm{O}$ (wt) ratio as 3.30 . The solution as it stands could be used in conjunction with suitable hardeners to achieve a solid product. However the water content was likely to be too high and the hardened matrix would shrink, exhibit little dimensional stability and probably cracks on curing process. To prevent this solid form of silicates P60 was identified and used as an effective adjustment agent to the compounding viscosity.

Table 1 The chemical and physical features of the liquid silicates ${ }^{9}$.

\begin{tabular}{|l|c|c|c|c|c|}
\hline Grade & $\mathrm{SiO}_{2}: \mathrm{Na}_{2} \mathrm{O}(\mathrm{wt})$ & Total solid \% & Viscosity at $20{ }^{\circ} \mathrm{C}$ cps & $\mathrm{Na}_{2} \mathrm{O} \%$ & $\mathrm{SiO}_{2} \%$ \\
\hline 079 type & 3.30 & 38.1 & 500 & 8.85 & 29.25 \\
\hline 074 type & 3.37 & 36.2 & 150 & 8.25 & 27.90 \\
\hline
\end{tabular}

Table 2 The formulation of the powder silicates 9 .

\begin{tabular}{|c|c|c|c|c|c|}
\hline $\begin{array}{c}\text { Grade } \\
\text { Powder form }\end{array}$ & $\begin{array}{c}\text { Mean wt Ratio } \\
\mathrm{SiO}_{2}: \mathrm{Na}_{2} \mathrm{O}\end{array}$ & $\begin{array}{c}\text { Mean Mol Ratio } \\
\mathrm{SiO}_{2}: \mathrm{Na}_{2} \mathrm{O}\end{array}$ & $\begin{array}{c}\text { Mean } \mathrm{SiO}_{2} \\
\%\end{array}$ & $\begin{array}{c}\text { Mean total solids } \\
\%\end{array}$ & Bulk density g/Litre \\
\hline Crystal C & 2.00 & 2.06 & 53.00 & 80.0 & $400-500$ \\
\hline Crystal M (P60) & 3.30 & 3.41 & 61.50 & 80.0 & $550-650$ \\
\hline
\end{tabular}

Hardeners

Commercial hardening agents are available which take many forms. Based on previous experience with liquid silicate systems and the target processing temperatures, a modified aluminium phosphate compound sold commercially as Fabutit (Aluminium phosphates) was identified as being appropriate as hardener 10, produced by Chemische Fabrik Budenheim KG.

Fillers

The criteria of filler selection have to rely on the chemical and physical features of the ceramic resin system and possibility of their incorporating with fibres. And the main purpose of adding fillers to the matrix compound was to reduce the cost of the materials and provide extra functionalities, performance and for a better control of manufacturing process and the surface finishes of end products. To form the moulding composite, the metalsilicates (liquid Na-silicates and K-silicates) were selected as matrix or adhesive to combine glass fibres and fillers together to form the expected moulding compounds. Each compound had an identical matrix consisting of a metal silicate binding phase which contained particulate fillers such as Wollastonite, calcium carbonate, aluminium trihydrite (ATH), talc, mica, etc. Figure 1 shows one of the popular fillers, Wollastonite, widely used in the ceramic and polymer moulding composite industries. In the research, a standard formulation was developed and considered desirable to incorporate the fillers that would be a constant factor in all formulations but where additional or alternative filler types could also be added to modify the formulation for specific functional needs.

Candidate filler types for adding into the compound include: Calcium Silicates (Wollastonite $=$ FW), Martinel Trihyde $\left[\mathrm{Al}(\mathrm{OH})_{3}=\mathrm{ATH}=\mathrm{MT}\right.$ (trade name) $]$, Calcium carbonate (Millicarb - trade name), Talc (Migsil - trade name) and Silica/silica glass (Spheriglas), $\mathrm{SiC}$ and $\mathrm{SiN}$, etc. Some of these fillers have been used to formulate a range of trial compounds and the viscosity was examined using a Brookfield viscometer. 


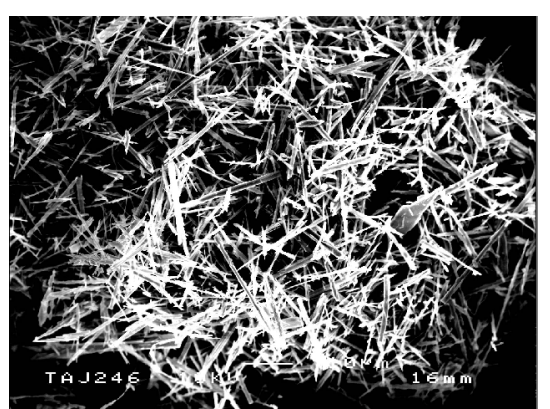

Figure 1 Crystal structures of Wollastonite (calcium silicates) is one of the important fillers used for ceramic and polymer moulding composites.

\section{Glass fibres}

The strength of the composites is provided by reinforcing fibres. Alkali-resistant (AR) glass fibres provided by Cem-FIL with more than $16 \%(\mathrm{wt})$ zirconia in their composition and durable in an alkaline environment as shown in Figure 2. Some of the properties of selected glass fibres are listed in Table 3 and different types of chopped AR-glass fibres, roving and E-glass fibres are listed in Table 4.

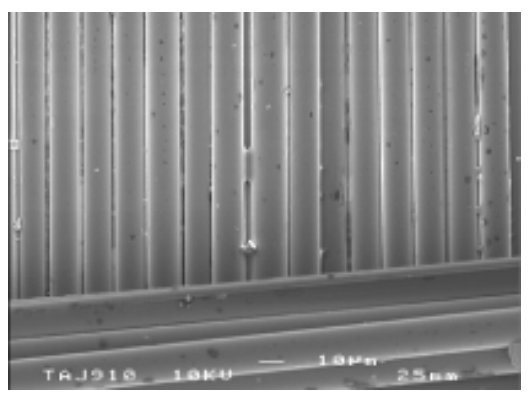

Figure 2 A SEM micrograph of the Cem-FIL AR 62/2 chopped fibre with length $12 \mathrm{~mm}$.

Table 3 Some physical and mechanical properties of A-glass, E-glass and AR glass fibres.

\begin{tabular}{|l|c|c|c|}
\hline Properties & A-Glass & E-Glass & Cem-FIL AR-Glass \\
\hline Specific gravity & 2.46 & 2.54 & 2.70 \\
\hline Tensile strength (MPa) & 3130 & 3448 & 2482 \\
\hline Modulus of elasticity (GPa) & 65 & 72 & 80 \\
\hline
\end{tabular}

Table 4 Different types of chopped AR-glass fibre, roving and E-glass fibre used for the CDMC in this work (Vetrotex and Cem-FIL technical specification, 1994 and 1996).

\begin{tabular}{|l|c|c|c|}
\hline Products & $*$ Cem-FIL 50/1 & \multicolumn{2}{|c|}{ Cem-FIL 62/2 } \\
\hline Length of the fibres & $12 \mathrm{~mm}$ & $6 \mathrm{~mm}$ & $12 \mathrm{~mm}$ \\
\hline Filaments per Strand & & 102 & 102 \\
\hline Strand Tex $(\mathrm{g} / \mathrm{km})$ & 76 & 38 & 38 \\
\hline Roving Tex & 2450 & & \\
\hline
\end{tabular}

*Cem-FIL 50/1 roving was chopped by a Glass chopper machine to $12 \mathrm{~mm}$ when used in the CDMC.

*Vetrotex SMC roving was chopped to $12 \mathrm{~mm}$ by a SMC machine when used in the CDMC.

\section{Manufacturing and moulding}

The moulding compounds studied were prepared by mixing the filler, matrix and fibre system in a Z-blade mixer prior to moulding. Compounds were prepared as shown in Figure 3 as an actual compound mixer in manufacturing process, with different fibre volume fractions of 15, 23 and $29 \%(w t)$ using $12 \mathrm{~mm}$ AR62/2 glass fibre. All hot-pressed compounds were left for 24 days at room temperature prior to moulding.

\section{Compounding process}

The z-blade mixing produces a random of 3D fibre dispersion in the dough form which is expected to flow during hot press moulding. This flowing capability will lead to form required complicated shaped structures.

The resin slurry and 6,12 and $24 \mathrm{~mm}$ chopped glass fibres were mixed respectively in a 10 litre lab scaled Zblade mixer to form the CDMC compound (intermediate). Following this, the moulding was carried out by 
placing a 500 g CDMC charge into a steel tool and compression moulding at $130-190{ }^{\circ} \mathrm{C}$ to generate sample plates for subsequent mechanical tests.

Moulding of the CDMC was carried out normally a week after the compounding made and it was later found that the shelf life of the ceramic compound could be extended to as long as 6 mouths, depending on the seals of the containers. Here the moulding compound and mould set are as shown in Figure 4. The mechanical properties of the moulding compound were dependent on the nature and volume fraction of the fibre reinforcement and the duration of the processing cycle.

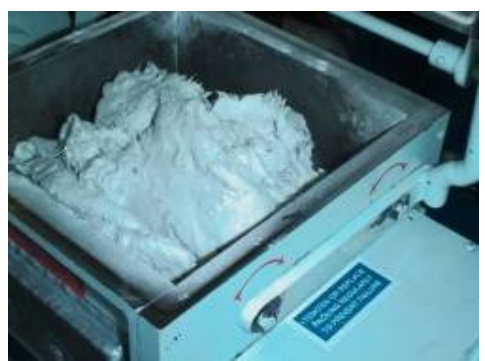

Figure 3 A DMC compounding machine using a twin Z-blade dough mixer.

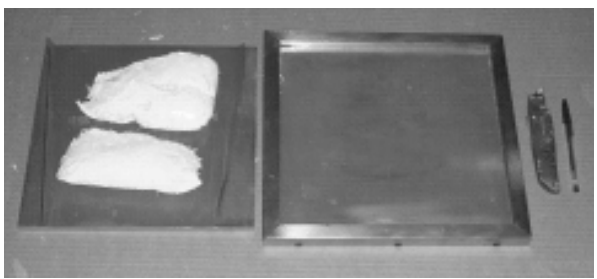

Figure 4 The low cost CDMC and the mould used for making CDMC panels for mechanical tests.

Preparation of testing materials

The testing panels from compounds were moulded at $130-190{ }^{\circ} \mathrm{C}$ by a compression moulding process under a pressure of 0.0-8.0 MPa based on the density requirement. Plates were produced with the size of approximately $300 \times 300 \mathrm{~mm}^{2}$ and thickness of $3-4 \mathrm{~mm}$. Then, the plates sectioned into smaller samples of size of $60 \times 60$ $\mathrm{mm}^{2}$ using a diamond saw for the mechanical and physical impact tests.

\section{Results}

Mechanical properties of the moulded CDMC

The mechanical properties of the moulded CDMC plates were tested with ISO standard and the results are listed in Table 6 with two different fibre reinforcements: alkaline resistant AR50/1 and AR62/2. The flexural properties of the CDMC plates using different matrix and different fillers were shown in Figure 5.

Table 6 Some basic mechanical properties of two CMC composites reinforced with different glass fibres.

\begin{tabular}{|l|l|l|}
\hline Properties & CDMC with AR50/1 & CDMC with AR62/2 \\
\hline Flexural strength $(\mathrm{MPa})$ & 82.0 & 120.0 \\
\hline Flexural modulus $(\mathrm{GPa})$ & 32.0 & 39.0 \\
\hline Tensile strength $(\mathrm{MPa})$ & 25.0 & 51.0 \\
\hline Tensile modulus $(\mathrm{GPa})$ & 39.0 & 42.90 \\
\hline Strain to failure in tension $(\%)$ & 0.10 & 0.24 \\
\hline Impact Energy absorption $(\mathrm{J}) /($ per $\mathrm{mm}$ thickness) & $0.1-0.2$ & $4.0-6.0$ \\
\hline Density $\left(\mathrm{g} / \mathrm{cm}^{2}\right)$ & 2.30 & 2.30 \\
\hline
\end{tabular}

Table 7 The viscosity requirement for the general DMC compounding.

\begin{tabular}{|l|l|l|}
\hline Time (days) & Directly after compounding & One week after compounding \\
\hline \hline Viscosity (mPa.s) & $5000 \sim 10000$ & $>=1 \times 10^{6}$ \\
\hline
\end{tabular}




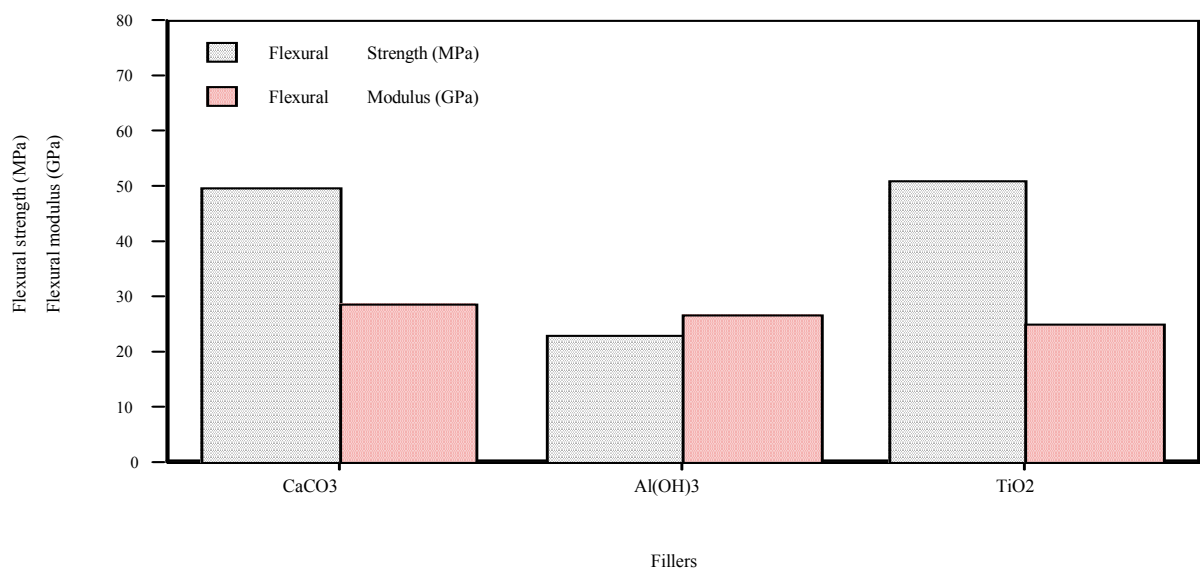

Figure 5 The flexural properties of the $\mathrm{CDMC}$ against different fillers, Millicarb $\left(\mathrm{CaCO}_{3}\right), \mathrm{Al}(\mathrm{OH})_{3}(\mathrm{ATH})$ and $\mathrm{TiO}_{2}$ using combination of ceramic matrix $+15 \%$ (vol.) AR50/1GF, moulded at temperature of $140{ }^{\circ} \mathrm{C}$.

\section{Discussion}

\section{Challenge for ceramic moulding compound}

The polymeric DMC is a material that is handlable in its unprocessed state at the room temperature. The basic requirements for a polymer dough moulding compound are viscosity control during storage or before moulding and its curing process. Normal moulding composites require a storage stability and flow-ability at processing temperatures (over $100{ }^{\circ} \mathrm{C}$ generally). This flow-ability allows the compounds to be transformed during the moulding into a required shape and then cured into a solid form with designed structural properties. These requirements are common irrespective of whether or not the composite material is polymeric or ceramic matrix based.

The hand-ability of the material at ambient temperature, and its ability to be moulded and to flow at processing temperatures are best described by idealised viscosity development against time plot as shown in Figure 6. The indicative lines illustrated a typical viscosity history of a polymeric matrix DMC. The required curve should reflect the ceramic matrix system to be as similar or as closer as polymeric matrix to the viscosity changes, which would be suitable for the real industrial manufacturing process. Specific data points from such target curve are given in Table 7. The final viscosity of the compound expected to be $>$ or $=1 \times 10^{6} \mathrm{mP} . \mathrm{s}(\eta$ is the viscosity in cps ( $1 \mathrm{cps}=1 \mathrm{mPa} . \mathrm{s})$.

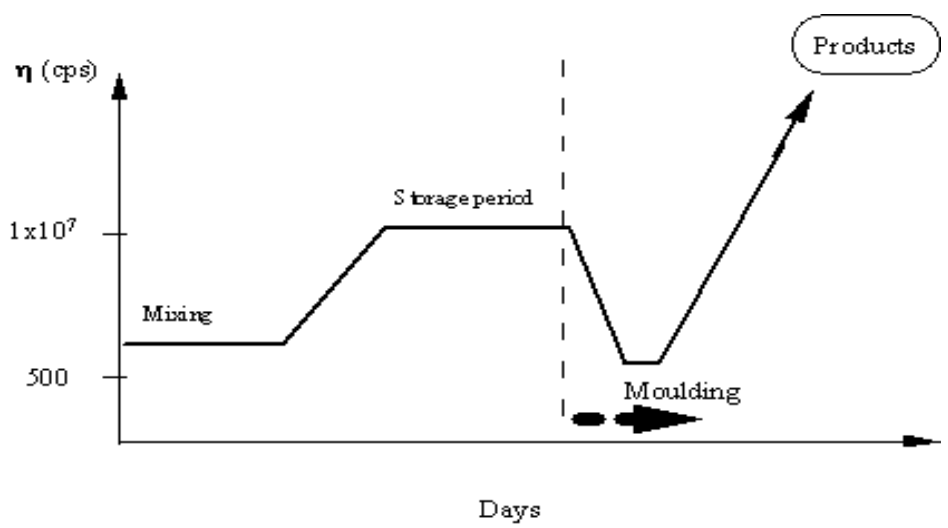

Figure 6 The ideal viscosity development of polymer and ceramic matrices for the moulding process required, with similar process conditions of compounding, thickening control, and moulding ( $\eta$ is viscosity in cps $(1 \mathrm{cps}=$ $1 \mathrm{mP} . \mathrm{s})$. 
Matrix resin system selection through viscosity tests

The compound is a matrix system based on the liquid metal silicates. It was liquid initially and can be transformed into a cross-linked three dimensional structure via the curing process (moulding) to provide the matrix with performance of 3-D cross-linking structure, while the viscosity control can be achieved by the introduction of the fillers and additives. These also provide a route to keep cost low, to improve dimensional stability, and ultimately to introduce functionality into the composites (e.g. to optimise fire resistance).

A range of solid silicates commercially were available and were added to the compounding solution to increase the solid content for increasing the matrix viscosity. Here, the P-type silicate (powder form) was selected for additive as it can be fully dissolved in the silicate solution at elevated moulding temperature. The dissolving of the silicates at the elevated processing temperature resulted in a reduction in viscosity and an increase in the overall silicate to water ratio. The effect of adding the solid P-type on the liquid viscosity is similar to that of adding other filler types during compounding processing. However, the advantage here is that the P-type silicate was dissolved into the liquid silicates during moulding and became the part of matrix resin system.

Hardening material and process selection

The Fabutit was added to the silicate solution as solid particles. This compound does not dissolve and accordingly must interact with the silicates on the particle surface. The Fabutit will increase the viscosity of the suspension both by virtue of its particulate nature and also by stimulating the polymerisation of the silicates illustrated in the group of indicative chemical reaction formulae.

$\mathrm{H}_{2} \mathrm{O}+\mathrm{M}_{2} \mathrm{O} \bullet x \mathrm{SiO}_{2}+\mathrm{PO}_{4}{ }^{3-}+\mathrm{Al}_{2} \mathrm{O}_{3} \rightarrow x \mathrm{H}_{2} \mathrm{SiO}_{3} \bullet \mathrm{H}_{2} \mathrm{O}+\mathrm{M}_{2} \mathrm{CO}_{3}+x \mathrm{Al}(\mathrm{OH})_{3}$

$\mathrm{H}_{2} \mathrm{SiO}_{3}+n\left(\mathrm{H}_{2} \mathrm{SiO}_{3}\right) \rightarrow(\mathrm{HO})_{3} \mathrm{SiO}-\left[(\mathrm{HO})_{2} \mathrm{SiOSi}(\mathrm{OH})_{2}\right]_{n}-\mathrm{OSi}(\mathrm{OH})_{3}$

A type of very fine Fabutit powder (320) has been examined as in the silicate matrix by TEM as shown in Figure 7. This compound effectively reacted with the liquid silicates to initiate or to create cross-linking 3-D chemical structures as follows.

The basic matrix system with hardener (silicates: hardener $=100: 5$ ) was examined as shown in Figure 7 by a Transmission Electron Microscopy (TEM) and the small particle islands of phosphate were observed in a two phase structure in the silicate matrix cured at $200{ }^{\circ} \mathrm{C}$. The poly-silicate glass presented a continuous phase while the hardener powder islands were uniformly distributed in the matrix. Surrounding the Fabutit particles sized around $1-5 \mu \mathrm{m}$, the needle like structure of the silicates appeared in the continuous glass phase. The sample structure appeared amorphous while the Fabutit was crystalline structure, as in its original powder form.

It is important that additional Fabutit did not result in a rapid reaction at room temperature, and did not as a consequence result in an unacceptable increase in viscosity. Based on the basic viscosity recommendation, a Fabutit content of 5\% (wt) in the matrix was chosen as fixed level for duration of this project.

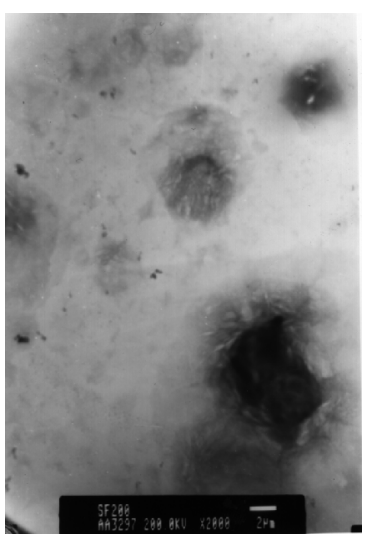

Figure 7 The Fabutit 320 particle TEM image with a silicate matrix presented as islands.

\section{Effectiveness of fillers}

Fillers are important constituents for all polymer and ceramic compounds in terms of costs, physical, chemical, thermal and mechanical properties. The combination of liquid metal silicates, P-type silicates and Fabutit hardener has resulted in a stable system where the viscosity of the matrix can be allowed to be increased in a controllable way. This actually formed the processing base for the composite matrix compounding. Accordingly it was necessary to include some solid form of particulate fillers such as Wollastonite, calcium carbonate and aluminium trihydroxide, etc as part of the standard matrix formulation to raise the viscosity to the appropriate level. This will reduce cost and improves dimensional stability for moulded products. 
Reinforcement-glass fibres

In the control compound the fibre was a conventional E-glass as used for reinforcing polyester resin moulding composites. The fibres used in this project concerning compatibility with liquid silicates $(\mathrm{pH}>10)$ were alkali resistant AR-glass AR50/1 and AR62/2 supplied by Cam-Fil Ltd, a French glass fibre manufacturer. The two different versions of AR glass fibres differed in their surface finish or sizing for different application areas. Different bonding produced by sizing coupling agents offered various bonding strength with the ceramic matrix system. AR50/1 was developed for providing better bonding with cement and AR62/2 chopped glass fibre was designed for improving the toughness of cement materials as shown in Figure 2. Vetrotex E-glass (Tex 2450 for polymer Sheet Moulding Compound and Dough Moulding Compound), Cem-FIL 50/1 and 62/2 roving were typical E-glass and AR-glasses for the reinforced moulding composites. Therefore, these fibres have been used throughout this research program. Based on the observation Cem-FIL fibres, it was found that AR 62/2 glass fibre was able to resist a very high alkalinity produced by the hydration of alkaline matrices, while under the same condition the E-glass was severely corroded and resulted in a significant decrease in mechanical properties. This part of work will be covered by other following-up papers.

Viscosity control of the compounds

In the manufacturing process, raw material selections and preparations can determine the viscosity of ceramic slurries. A well controlled viscosity is a necessary condition for a successful moulding in order to achieve a qualified product. Based on the compound viscosity data, it was apparent that maximum filler content (irrespective of the filler type) around 30-50\%(wt.) was permissible for adding glass fibre in the following-up processing.

From the range of the fillers studied, the ATH and the Wollastonite (FW) was selected as standardised base fillers for the system. They bond very well with the matrix silicates when it hardens. A minimum level of 15 $20 \%$ (wt.) ATH or FW was added to matrix compositions with total filler content as high as $50 \%$ (the maximum). Aluminium trihydroxide (ATH) was added for the special requirements such as for extra-fire performance. Other fillers including P-type solid silicates, Fabutit, etc. were adjustable according to the needs for cost, slurry viscosity, mechanical and thermal properties.

As described above the viscosity makes a significant influence on the production efficiency, surface quality and even the mechanical properties of the finished products. For liquid silicates and their slurries after liquid silicate slurry mixing as required by the viscosity window for the $\mathrm{CDMC}$, viscosity development process took place in two stages. First one presumably was a Newtonian stage, and followed by a Non-Newtonian stage after mixing with the hardeners and the fillers. The effects from hardener and fillers on the matrix viscosity provided the viscosity characterisation of a Non-Newtonian fluid of the matrix system.

\section{The concept of a formulation}

The options available to formulate a moulding compound could be many and, as such, a decision was taken at an early stage in this research to rationalise the development of a range of materials based on a relatively standard basic formulation. This consisted of a mixture of liquid silicates, a curing or hardening agent, and base filler. All other fillers can be added to introduce additional mechanical properties or functionalities.

The formulation for the matrix designated as SF-II (Standard Formulation II) was selected on the basis of the best processing practice. All the other matrix compositions with different functions for various applications were derived from this matrix formulation. As shown in Figure 8, the SF-II was basically formulated with liquid silicates, hardener and mineral fillers based on their effects on the processing viscosity. The glass fibre $\mathrm{E}$ or A type was also used, and the range of fibres can be also selected based on the different applications.

Figure 8 shows the viscosity curve of a typical compound slurry system vs. time using 5.0\%(wt.) Fabutit as the hardener. Measuring at $20^{\circ} \mathrm{C}$, the matrix presented a perfect viscosity increase rate similar to those of polymer SMC/DMC matrix. Adding the Fabutit to the mixture increases the viscosity quick as expected. The final viscosity of the matrix could be reached to $1.0 \times 10^{7} \mathrm{mPa}$.s after the compounding process for $2 \sim 3$ days. The viscosity of the material can be stable for 6 months.

Table 8 The formulation of SF-II plus AR/E-glass fibre for the CDMC for general applications.

\begin{tabular}{|l|l|}
\hline $\begin{array}{l}\text { Formulation of the } \\
\text { moulding compound (SF- } \\
\text { II) }\end{array}$ & $\begin{array}{l}\text { \%(wt) } \\
\text { different raw } \\
\text { materials }\end{array}$ \\
\hline Crystal 079 & $35.0 \%$ \\
\hline Wollastonite (FW)/ATH & $15.0-20.0 \%$ \\
\hline P-type & $4 \%$ \\
\hline Hardener (Fabutit 320) & $2-5 \%$ \\
\hline
\end{tabular}




\begin{tabular}{|lll|l|}
\hline Glass fibre & (E-glass & or & $0-35$ \\
AR-glass: AR50/1 & or & \\
AR62/2) & & & \\
\hline
\end{tabular}

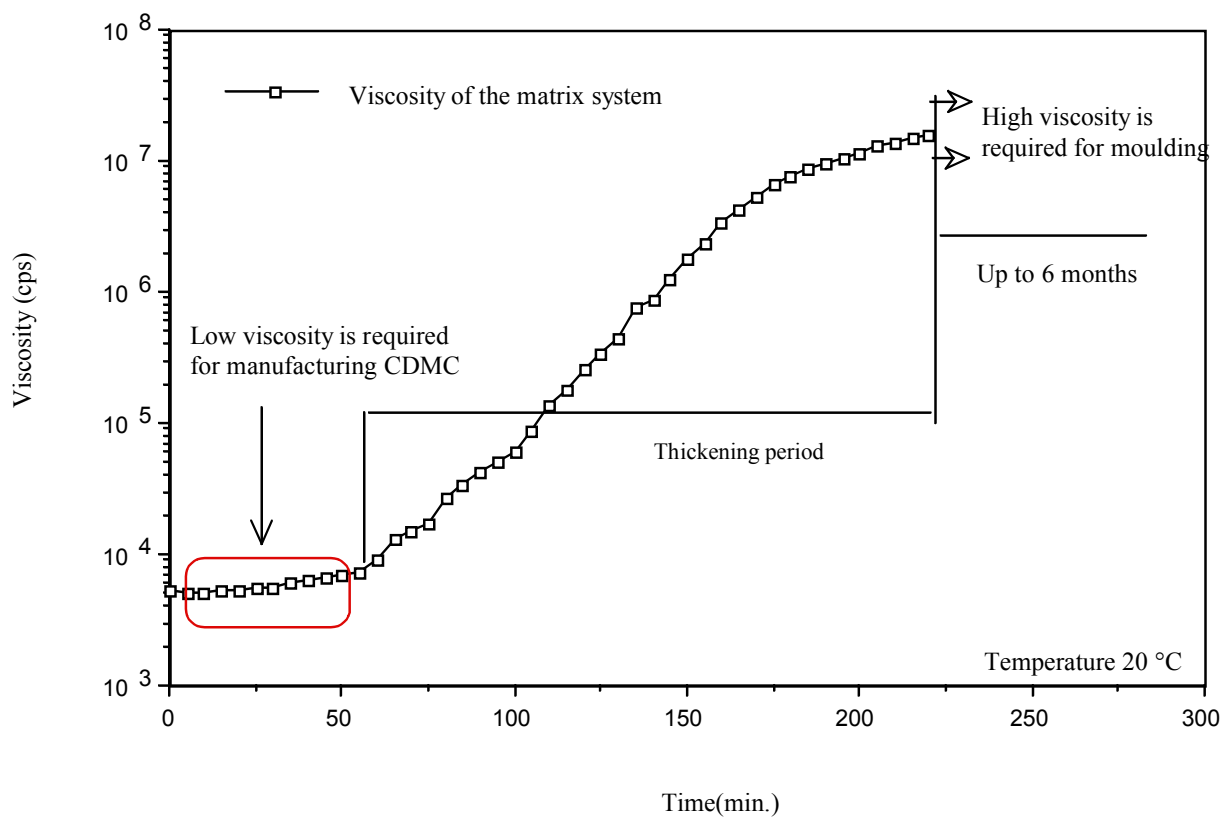

Figure 8 The viscosity of a typical compound slurry system vs. time, using $5.0 \%(w t$.$) Fabutit as the hardener,$ measured at $20^{\circ} \mathrm{C}$ (viscosity: $1 \mathrm{cps}=1 \mathrm{mPa} . \mathrm{s}$ ).

\section{Characterisation of the moulded CDMC structure and analysis}

The combination of the developed matrices and variation plus glass fibres has produced the proper moulding compound identified as ceramic dough moulding compound (CDMC). It resulted in a visible ceramic sheet or dough moulding composite. Two SEM micrographic images of the matrix shown in Figure 9, revealed a continuous silicate matrix phase, filler particles and the bundles of glass fibres uniformly distributed in the moulding composites.

In the formulation, the glass fibre fraction in the composites was designed to be adjustable from $0 \%$ (vol.) to about $30 \%$ (vol.) depending on the filler types and the amount of loadings where reaching a point starting to be difficult to obtain a full wet-out of the fibre. Most of the SEM images have shown three dimensional (3-D) distributions of chopped fibres with orientations more affected by in-mould flow pattern under moulding temperatures as shown in Figure 10, where it is a slightly different image to the imagined 3-D image of chopped or short fibre composite cross-section distribution. This optical cross-section CDMC with flow pattern of chopped fibre bundles was shown throughout the cross-section moulded panel (thickness $3.1 \mathrm{~mm}$ ). The orientation pattern of the fibre bundles indicated their travel experience during the moulding.

Varieties of formulated CDMC were prepared at the room temperature with a standard compounding process. In order to get special effect, the viscosity can be adjusted high or low for some special applications such as thin panels and complicated shaped products. Then the compound with much higher viscosity should be heat treated prior to moulding for achieving a better flow. 

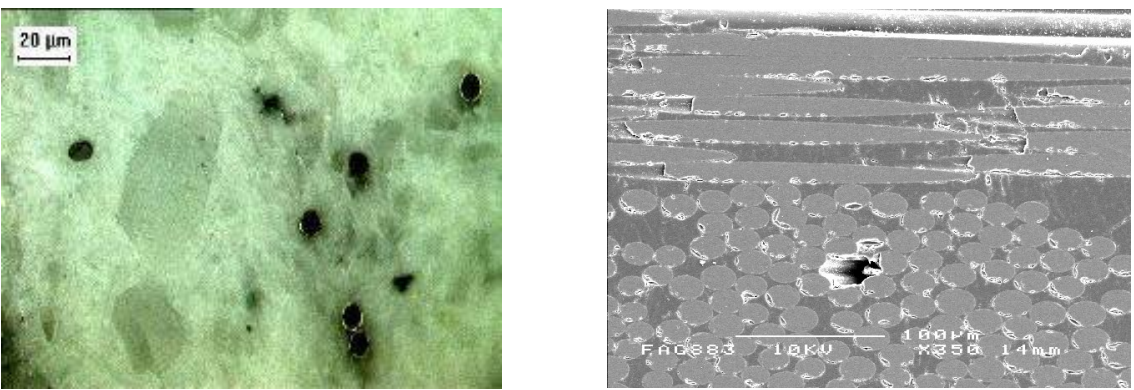

Figure 9 Filler particles and glass fibres uniformly distributed in the ceramic based composites and silicates matrix formed a continuous phase.
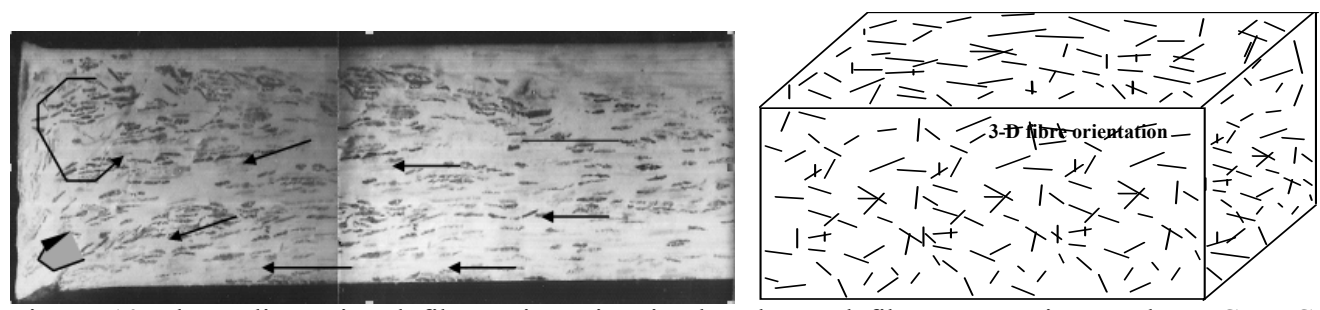

Figure 10 Three dimensional fibre orientation in the chopped fibre composites such as CDMC. The optical micro-graph of a CDMC (left) with flow pattern of chopped fibre bundles throughout the cross-section of moulded panel with thickness of $3.1 \mathrm{~mm}$.

Composition analysis -Glass fibre volume fraction

The volume fractions of the glass fibres in the CDMC are defined by its formulation before moulding and the weight difference of the plates before and after moulding within the mould, as well as the density of a moulded $\mathrm{CDMC}$ panel. The weight difference is mainly coming from the water evaporation during the moulding.

For example, the glass fibre volume fraction of the composites could not be obtained as the same way as polymer composites by through chemical decomposition or burning process, etc. However, the normal calculation should sever the purpose as shown in following equations:

$V_{f} \%($ vol. $)=\frac{V_{\text {fibre }}}{V_{C D M C}}=\frac{W_{f} / D_{f}}{W_{C D M C} / D_{C D M C}}=\frac{W_{f}}{W_{C D M C} \cdot D_{C D M C}}=\frac{D_{f D M C}}{D_{f}} \bullet W_{f} \%(w t$.

Where:

$D_{f}$ :

$D_{C D M C}$ :

$V_{f}:$

$V_{C D M C}:$

$V_{m}:$

$W_{f}$ :

$W_{C D M C}$ :

$W_{f}:$

density of the glass fibre;

density of the CDMC, measured;

fibre volume fraction in the CDMC;

volume of the CDMC composite;

volume fraction of the matrix in the CDMC;

weight of the glass fibre;

weight of the CDMC;

weight percentage of the glass fibre.

The equation is the relationship between a glass fibre volume fraction and the weight percentage for the particular CDMC. The results of this equation and experimental density obtained in the tests for the CDMC appealed that, the density of the $22.6 \%$ (vol.) $\mathrm{CDMC}\left(8.0 \mathrm{MPa}, 130{ }^{\circ} \mathrm{C}\right.$ moulded) was less than the density of glass fibre, due to the less dense matrix system $\left(\mathrm{D}_{\mathrm{CDMC}}=2.22-2.24\right)$.

If the weight and volume fraction were increased for a particular glass fibre, the volume fraction of the matrix would be decreased. It was noted that when the weight percentage of glass fibre exceeded $30 \%$ (wt.), it could be difficult to process based on the baseline matrix formulation.

Basic mechanical properties of the CDMC

Basic mechanical properties of the CDMC were established using baseline formulation incorporated by glass fibre AR50/1 and AR62/2 as listed in Table 4 and Table 8. The CDMC reinforced with AR62/2 presented the best mechanical properties among the all, which were very close to conventional polymeric Dough Moulding 
Compounds (DMC). Due to the nature of ceramics in general, the CDMC modulus is higher compared with polymer DMC composites, while the impact properties are significantly improved to the level $(4-5 \mathrm{~J}$ per mm thickness) where very close to conventional polymer DMC. Due to the requirement of cost-effectiveness, in general industrial practice, the mechanical properties are always depended on the level of fillers used in the composites.

Originally, the major selection criteria for fillers were their chemical and physical compatibility with a baseline matrix covering Wollastonite, ATH (trademark MT), Spheriglass powder, Millicarb and Talc, etc. The mechanical properties using popular fillers were evaluated and selected fillers based on availability and compatibility. The reason for using these fillers was that they are environmentally stable, commercially available, low cost and are popular fillers used in polymer and ceramic composites. For example, ATH was believed to be one of the best fire retardant minerals, as a large amount of chemically bonded water released when subjected to heat or fire. The Wollastonite and Talc are minerals having the basic chemical structure of mineral silicates compatible to the liquid silicates and thermally stable over $1000^{\circ} \mathrm{C}$.

Two sections of the tests were carried out and they were the CDMC with general fillers and the CDMC with the silicates minerals. Firstly, general fillers of Calcium Carbonate, $\mathrm{ATH}$ and $\mathrm{TiO}_{2}$ powders were used. The second types were Crystobalite, T85 (ceramic foamed particles), grinding glass powder (Spheriglass), Wollastonite (FW) and a Talc, all have similar structures to mineral silicates. It was found that the CDMC with FW has the higher flexural strength which was $57 \mathrm{MPa}$ and the Talc filled CDMC achieved the highest modulus of $35 \mathrm{GPa}$. The metallic silicates such as glass powder containing $\mathrm{Ca}^{2+}, \mathrm{Al}^{3+}$ silicates and Talc are more compatible with the matrix system and lead to slightly better flexural properties.

In order to establish a standard matrix system, fillers needed to be not only compatible with silicates but also assistant to the manufacturing process. It was observed that $\mathrm{FW}, \mathrm{ATH}, \mathrm{Talc}, \mathrm{CaCO}_{3}$ and $\mathrm{TiO}_{2}$ presented the best mechanical properties, while all of them were compatible with the manufacturing procedures.

As a result of this investigation, therefore, in formulation SF-II (as standard formulation), ATH and FW were selected as the basic filler, for achieving best manufacturing process and mechanical properties.

\section{Conclusion}

A new class of cost effective mouldable ceramic composites -the low cost CDMC has been produced in the way exactly as close as possible as polymeric DMC, but offering higher temperature performance coupled with reasonable mechanical properties especially improved impact properties ${ }^{8}$. The material was developed based on the concept of the polymer dough moulding and sheet moulding compound material, but used the liquid metal silicates as the matrix resin and alkali resistant fibres as the reinforcement. These permitted the process cycle very similar in many respects to those of polyester or phenolic moulding compounds with low cost and fast production cycle.

The viscosity investigation in the process provided with a proper composition of matrix system for ensuring the compound to reach viscosity of $1 \times 10^{6} \mathrm{cps}$ within 24 hours after mixing. The glass fibre of the AR62/2 type was selected and optimised suitable for processing and moulding.

The whole process has revealed that an increase in viscosity was ideal for a stage of the compound storage, handling, and moulding. The matrix initial viscosity was, as expected, low enough to wet out the chopped glass fibre during processing. Then the viscosity of premixed paste after adding with chopped fibre glass can increase significantly $\left(>1 \times 10^{6} \mathrm{cps}\right)$. It was liquid initially and, via curing process, can be transformed into a cross-linked three dimensional structure to provide the matrix basis for the structural performance, while the viscosity control can be achieved through the introduction of the fillers and additives.

The major drawback of using soluble silicates in solution was that, during the hardening process, it was necessary to evaporate water from the compound in order to retain composites' dimensional stability.

The development of fibre and particulate filler reinforced ceramic composites provides a route to achieving increased toughness as well as fire resistance in the materials, although this is often at the expense of ultimate strengths and/or the process-ability of the materials.

\section{References}

1. Martin Grayson, editor, "Encyclopaedia of Glass, Ceramics, Clay and Cement", published by John Wiley \& Sons, Inc., pp 198-230, 1985.

2. KJD Mackenzie, IWM Brown, P Ranchod, RH Meinhold, "Silicates bonding of inorganic materials, Part II. Chemical reactions in sodium silicates at high temperature", Journal of Materials Science, Vol. 26. No. 3 pp. 769-775, 1991.

3. KJD Mackenzie; RH Meinhold; "A glass-bonded ceramic material from chrysotile (white asbestos)", Journal of Materials science, Vol. 29, No 10. pp. 2775-2783, 1994.

4. G. Ren, PhD Thesis, Queen Mary, University of London, 2000.

5. Aveston J, Kelly A, Journal of Materials Science, Vol. 8, P352-362, 1973. 
6. J Ambroise, J Dejean and J Pera, "Study of fibre matrix interfaces in metakaoline-OPC /blended cement GRC composites", Materials Research Society "Bonding in Cementitious Composites" Symposium Proceedings. P175, Volume 114, December 1987, Boston, USA.

7. RP Banas, et al., "Lessons learned from the development and manufacture of ceramic reusable surface insulation (RSI) materials for space shuttle orbiters," NASA/LARC conference "Shuttle Performance: Lessons Learned," Langley Research Centre, March 8-10, 1983.

8. G. Ren, P. J Hogg and D. H. Woolstencroft, "Low cost ceramic moulding composites: impact properties" British Ceramic Transactions, 2004 Vol. 103 No. 4.

9. Cem-FIL International Ltd "Data sheets of AR glass fibre", 1996.

10. Specification of Crosfield, 1994.

11. CFB Budenheie, FABUTIT320 -Hardener for sodium silicate bonded masses and mortars, 2000.

12 J. Aveston, G. A. Cooper and A. Kelly, conference proceedings. National Physics Laboratory (IPC), 1971. 
* Response to reviewer comments
\[ \begin{array}{l}\text { Response to revi } \\ \text { Paper uploaded } \\ 04 / 03 / 08\end{array} \]

Rer comments
Paper uploaded by J Crocker, No RtRC given
04/03/08

* Response to reviewer comments
\[ \begin{array}{l}\text { Response to reviewer comments: } \\ \text { Paper uploaded by J Crocker, No RtRC given } \\ \end{array} \]

\author{
Response to reviewer comments:
Paper uploaded by J Crocker, No RtRC given
04/03/08
}

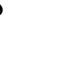

Paper uploaded by J Crocker, No RtRC given
/03/08

Paper uploaded by J Crocker, No RtRC given
04/03/08

Paper uploaded by J Crocker, No RtRC given
(03/08

Paper uploaded by J Crocker, No RtRC given
/03/08

.

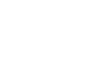

aper uploaded by $J$ Crocker, No RtRC given
$0403 / 108$

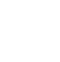

